\title{
Nanorod-structured $\mathrm{Fe}_{3} \mathrm{O}_{4} /$ Graphene Nanocomposite as High Performance Anode for Lithium-Ion Batteries
}

\author{
Yanglin Liu ${ }^{1,2}$, Yaping Wang ${ }^{1}$, Anqiang Pan ${ }^{1, *}$ \\ ${ }^{1}$ School of Materials Science and Engineering, Central South University, Changsha, Hunan 410083, \\ China \\ ${ }^{2}$ Changsha Environmental Protection Vocational College, Changsha 410004, Hunan, China \\ *E-mail: pananqiang@ csu.edu.cn
}

doi: $10.20964 / 2017.03 .71$

Received: 24 October 2016 / Accepted: 19 January 2017 / Published: 12 February 2017

High capacity $\mathrm{Fe}_{3} \mathrm{O}_{4}$ nanorod/graphene composites with good rate capability were prepared by a twostep synthesis process: FeOOH/graphene composites were first synthesized by uniformly dispersed, hydrothermal prepared $\mathrm{FeOOH}$ nanorods on functionalized graphene sheets, and then they were annealed in an argon atmosphere at $450^{\circ} \mathrm{C}$ for $2 \mathrm{~h}$ to make $\mathrm{Fe}_{3} \mathrm{O}_{4} /$ graphene composites. The graphene functions as a reducing reagent during the annealing process. Thus synthesized $\mathrm{Fe}_{3} \mathrm{O}_{4}$ nanorods with small diameters ranging from $50 \mathrm{~nm}$ to $100 \mathrm{~nm}$ have an intimate electrical contact with graphene sheet and exhibit excellent electrochemical properties. $\mathrm{The} \mathrm{Fe}_{3} \mathrm{O}_{4}$ nanorod/graphene nanocomposite shows a superior high reversible specific capacity $\left(1155 \mathrm{mAh} \mathrm{g}^{-1}\right)$ and good rate capability, demonstrating it is a promising alternative electrode material for high-performance lithium-ion batteries.

Keywords: graphene; $\mathrm{Fe}_{3} \mathrm{O}_{4}$ nanorod; anode; lithium-ion batteries; high rate

\section{FULL TEXT}

(C) 2017 The Authors. Published by ESG (www.electrochemsci.org). This article is an open access article distributed under the terms and conditions of the Creative Commons Attribution license (http://creativecommons.org/licenses/by/4.0/). 